\title{
Berichtigung der Erwiderung des Herrn Mank-Mylau.
}

Von Arthur Meyer.

Das Manuskript der vorstehenden Erwiderung war mir von dem Herrn Redakteur des Archivs zur Einsicht vorgelegt worden, weil er der Meinung war, daß es nötig sei den Herrn Autor der Erwiderung zu einer Aenderung der Form des gegen mich gerichteten Angriffes zu veranlassen. Ich habe gebeten, davon abzusehen, da ich meine, daß diese Form zu verzeihen wäre, wenn ich den Apothekerstand wirklich so beleidigend angegriffen hätte, wie der Autor annimmt. Die etwas schroffe Form liefert ja den besten Beweis dafür, daß er fest überzeugt ist, daß in meiner in erster Linie für den Pharmakognosten geschriebenen Abhandlung Beschuldigungen des Apothekerstandes enthalten seien.

Ich meine, daß die Vorwürfe, welche mir der Autor macht, nur deshalb von ihm erhoben werden konnten, weil er nicht genügend mit der Materie vertraut, in einer mir verständlichen, aber hier unrecht angebrachten Empfindlichkeit, die unser A p ot hekerstand nicht zu besitzen braucht und wohl auch nicht besitzt, Dinge aus dem von mir Gesagten herauslas, welche gar nicht von mir gesagt worden sind.

Der Autor sagt, ich hätte die Beschuldigung gegen den Apothekerstand ausgesprochen: „daß in den Apotheken nur für die Revision vorschriftsmäßige Ware vorrätig gehalten würde, während zur Verarbeitung billigere, minderwertige, den Anforderungen des Arzneibuches nicht entsprechende Ware Verwendung fände".

Zuerst habe ich nun nicht gesagt, daß Revisionsware von Strophanthusfrüchten vorrätig gehalten würde. Es gibt ja jetzt noch gar keine solchen Früchte im Handel. Ich habe ausgesprochen, daß die Möglichkeit vorhanden wäre, daß das einmal geschehen $\mathrm{k}$ ö $\mathrm{n}$ e. Ich halte es nicht für zweckmäßig hier über den Begriff der Revisionsware zu reden, bemerke nur, daß ich es für gar nicht verwerflich halten würde, wenn de: Apotheker möglichst schöne Strophanthusfrüchte für die Revisoren aufbewahren würde, wenn einmal die Früchte offizinell werden sollten. Ich habe dann weiter gemeint, daß es dann vorkommen könne, daß für die Bereitung 
der Arzneien „billigere, nackte Samendroge Verwendung fjnden könne $e^{6 \text {. }}$.

Aus diesem Satzteile macht der Autor: ,billigere, minderwertige, den Anforderungen des Arzneibuches nicht entsprechende Ware". Ich habe aber nur billigere gesagt, und der Satzteil wird von dem, welcher die Materie beherrscht, folgendermaßen verstanden werden.

Wenn die Frucht von Strophanthus in das Arzneibuch Aufnahme finden würde, so würde unter allen Umständen den Samen der offizinellen Früchte ganz gleichwertiger nackter Samen im Drogenhandel billiger werden als die in den Früchten enthaltenen Samen und zwar deshalb, weil die ganze Frucht beim Trocknen viel leichter dem Verderben ausgesetzt ist als der von den Sammlern herausgenommene Samen, weil ferner die Kontrolle der in der Frucht enthaltenen Samen durch den Importeur viel unsicherer ist und leicht unbrauchbare Früchte mit eingeführt werden, weil schließlich der Transport der Samen in den Früchten etwas teurer ist als der der nackten Samen. Das, was ich hier ausgeführt habe, liegt dem Worte "billigere" bei mir zugrunde; man sieht, daß die Erläuterung des Autors ,minderwertige, den Anforderungen des Arzneibuches nicht entsprechende" durchaus unzutreffend ist. Es ist nun weiter eine Tatsache, daß das Herausnehmen und Reinigen der Samen aus den Früchten eine recht unangenehme Arbeit ist, und daß es deshalb sehr nahe liegen würde beste nackte Samendroge statt der völlig gleichwertigen Frucht zu beziehen, so daß es vielleicht doch einmal einen Apotheker geben könnte, der im guten Glauben oder aus Zweckmüßigkeitsgründen die besten nackten Samen statt der Früchte kaufen könnte.

1)er Autor könnte auch nun noch sagen: ,auch das kann niemals in einer Apotheke vorkommen!", aber der A p ot h ek ers $t$ a n $d$ wird das. nicht sagen, denn er ist so klug, da $\beta$ er wei $\beta$, da $\beta$ schlimmere Dinge in jedem Stande vorkommen können. da sich auch der beste Stand aus guten und schlechteren Mitgliedern zusammensetzt, und daß deshalb erst der Beweis geliefert werden müßte, daß es gerade im Apothekerstande anders sei. Wenn jemand. der es mit einem Stande gut meint, Gesetze für diesen machen will, so mußs er immer darauf bedacht sein, sie so zu gestalten, daß zu ihrer Uebertretung möglichst wenig Möglichkeiten und Veranlassung vorliegen, denn dann kann dem Stande aus dem Gesetze möglichst wenig Nachteil bezüglich seines Ansehı.ns erwachsen. Nur von dem Gesichtspunkte aus, daß ich unserem tüchtigen deutschen Apothekerstande, ebenso wie dem Arzte und dem Publikum 
nützen wollte, sind diese meine sachlichen Auseinandersetzungen zu beurteilen.

Der zweite Vorwurf, den mir der Autor macht, bezieht sich darauf, da $B$ ich gesagt habe, daß schon sogleich nach dem Erscheinen der 4. Ausgabe des Arzneibuches, bei genauer Berücksichtigung der Diagnose des Arzneibuches der Apotheker habe echte Pharmakopöeware führen können, und daß dann, wenn das nicht durchaus geschehen sei, dieses nur auf ungenügende Schulung in pharmakognostischer Beziehung oder auf ungenügender Prüfung der Drogen habe beruhen können. Nur für denjenigen, welcher nicht mit den pharmakognostischen Verhältnissen der Droge vertraut ist, muß ich hier hinzufügen, daß sich dieser Satz gegen die Meinung richtet, daß die Fassung der im Arzneibuche enthaltenen Diagnose der Strophanthussamen daran schuld sei, daß die Strophanthuspräparate so verschiedenartig wirksam gewesen seien.

Führe ich den Satz also allgemein verständlicher aus, so könnte er folgendermaßen lauten: ,wenn das nicht durchaus geschehen sein sollte, so liegt das nicht an der Diagnose des Arzneibuches, sondern könnte dann nur an ungenügender pharmakognostischer Schulung oder an nicht sorgfältiger Prüfung liegen.

Da der Satz so gemeint war, so brauche ich nicht über den Umfang der pharmakognostischen Schulung des Apothekerstandes zu reden, und auch die Frage, wie die Strophanthusdroge beschaffen gewesen sei, welche nach 1900 in die Apotheken gelangte, kann ganz unerörtert bleiben. Ueber die pharmakognostischen Exkurse des Autors darf ich mit Stillschweigen hinweggehen, da der einigermaßen Orientierte ihren Wert ohne weiteres erkennen wird. Ich hätte überhaupt den ganzen Angriff ignoriert, wenn ich nicht befürchtet hätte, daß gerade die unrichtige Interpretation der besprochenen Sätze durch Herrn Mank-Mylau dem Apothekerstande ein wenig schaden könne. 